\title{
The Prognostic Value of Initial Tumor Size in Patients with Ewing Family of Tumors
}

\author{
Rajeeb Kumar Deo ${ }^{1}$, Prakash Chitalkar ${ }^{2}$, Amit Joshi ${ }^{1}$, Sushil Ranamagar ${ }^{1}$ \\ ${ }^{1}$ Department of Medicine, Shree Birendra Hospital, ${ }^{2}$ Sri Aurobindo \\ Institute of Medical Sciences, Indore
}

\begin{abstract}
Introduction: Ewing Family of Tumors (EFT) is a high grade embryonic malignancy, common in children and young adults (CYAs). The prognostic factors include initial tumor volume, site, presence of metastasis, and the EWS/FLI 1 mutation. Low volume disease is known to result in higher response rates and longer survival times.

Methods: Twelve patients with non-metastatic EFT were managed with the intensive Ewing Family Tumor (EFT 2001) protocol. The patient characteristics studied were - age, sex, site, number of sites involved, bone marrow involvement and size (volume). Tumor volume was measured in non-metastatic tumors by tridimensional volume in MRI scans.

Results: Progression free survival (PFS) of patients with initial tumor volume $\leq 100 \mathrm{cc}$ ranged from 30 months to 74 months (mean 56.4 months) while that for $>100 \mathrm{cc}$ ranged from 19 months to 79 months (mean 40 months) (p value: 0.701 ). However there was trend towards better survival in patients with initial tumor volume $\leq 100 \mathrm{cc}$.
\end{abstract}

Conclusions: There is a trend towards better PFS in patients with smaller tumor volume at presentation. Thus initial tumor volume is a prognostic factor in Ewing family of tumors.

Keywords: ewing family of tumors; tumor size; progression free survival; EFT 2001.

\section{INTRODUCTION}

Ewing's sarcoma belongs to the Ewing Family of Tumors (EFT), which comprises a group of small round cell neoplasm of neuroectodermal origin and includes the primitive neuroectodermal tumors $(\mathrm{PNET})^{1}$. EFT is a high grade embryonal malignancy, common in children and young adults (CYAs). The prognostic factors include initial tumor volume, site, presence of metastasis, and the EWS/FLI 1 mutation ${ }^{2}$. In a community oncology centre in this part of the world, patients usually present late due to various reason like ignorance, poverty and lack of easy access to medical centre and high volume disease is common at presentation. Low volume disease is known to result in higher response rates and longer survival times ${ }^{3}$.
The aim of this study was to assess the prognostic impact of initial tumor volume on the progression free survival of CYAs with EFT when treated on an intensive protocol of chemo radiation.

\section{METHODS}

In this cross sectional observational study, 12 patients with non-metastatic EFT were managed with the intensive Ewing Family Tumor protocol (EFT 2001) ${ }^{4}$ from 2006 to 2011. Twelve consecutive patients, irrespective of age, sex and site of disease were included in this study. The patient characteristics studied were age, sex, site, number of sites involved, bone marrow involvement and size (volume). Tumor volume was measured in non-metastatic tumors by tri-dimensional volume in MRI scans. PFS was recorded in all patients
Correspondence
Lt Col Dr. Rajeeb Kumar Deo
Medical Oncologist
Department of Internal Medicine
Shree Birendra Hospital, Chhauni, Kathmandu
Email: rajeebdeo@yahoo.com 
after minimum of 24 months of follow up.

The initial tumor volume was documented at diagnosis with tri-dimensional measurements in MRI scan. Clinical parameters and serum LDH were also recorded. The histology was obtained by incisional / excisional biopsy and only those cases with proven histologic diagnosis were included in the study. Immunohistochemistry (IHC) with CD 99 was done in all biopsies. Other IHC markers studied were CD 45, S 100, Vimentin, Desmin and Myosin.

Treatment schema was based on EFT Protocol ${ }^{4}$. All patients were started on alternating cycles of VIE (Vincristine, Ifosfamide with mesna, Etoposide) and VAC (Vincristine, Adriamycin, Cyclophosphamide) every 3 weeks for total of 4 cycles. Then all patients were taken for local therapy with either surgery or radiation. After local therapy, patients were continued with alternating cycles of VAC and VCD (Vincristine, Cyclophosphamide, Actinomycin-D) every 3 weeks for total of 13 cycles.

All patients received standard doses as per protocol (Table 1). However dose adjustments were done according to Eastern Cooperation Oncology Group - Performance status (ECOG PS) ${ }^{5}$ and patient's tolerability to chemotherapy. G-CSF was used as needed during the treatment. After 4 cycles of induction chemotherapy, 5 patients underwent primary resection of the tumor osseous 2 - scapular and extra osseous 3. Remaining 7 patients received radiation therapy as consolidation. All patients completed remaining cycles of chemotherapy.

Patients were followed up every 3 months for a minimum of 24 months, with clinical examination and $\mathrm{X}$ ray. MRI was done if indicated. Maximum period of follow up was 79 months.

Table 1: Drug dosages and administration schedule
V-Vincristine, I-Ifosfamide with mesna, E-Etoposide, A-Adriamycin, C-Cyclophosphamide, D-

Actinomycin-D

\section{RESULTS}

Demographic data of patients included in this study are shown in Table 2 and 3. Initial tumor volume ranged from $20 \mathrm{cc}$ to $1050 \mathrm{cc}$ (mean $265.58 \mathrm{cc}$ ). The tumor volume was $\leq 100 \mathrm{cc}$ in 4 patients and $>100 \mathrm{cc}$ in 8 patients (Figure 1). Mean age in the two groups, $\leq 100$ $\mathrm{cc}$ and $>100 \mathrm{cc}$ were 11.516 and 19.714 respectively, with $\mathrm{p}$ value of 0.012 . The distribution of sex, site and bone marrow involvement among the two groups were not statistically significant with $\mathrm{p}$ values $0.408,0.198$ and 0.735 respectively (Table 2 ). Site of tumor were varied with 3 patients having tumor in humerus, 2 each in femur and pelvic region (Figure 2).

\section{Table 2: Patient profile}

\begin{tabular}{|c|l|c|c|c|}
\hline \multirow{2}{*}{$\begin{array}{c}\text { Demography A } \\
\text { cc }\end{array}$} & \multicolumn{2}{|c|}{ Group } & \multirow{2}{*}{$\begin{array}{c}\text { P } \\
\text { value }\end{array}$} \\
\cline { 2 - 4 } & $\begin{array}{c}\text { B > 100 } \\
\text { cc }\end{array}$ & & \\
\hline \multicolumn{2}{|c|}{ Age ( Mean) } & 11.516 & 19.714 & 0.012 \\
\hline \multirow{2}{*}{ Sex } & Male & 4 & 4 & \multirow{2}{*}{0.408} \\
\cline { 2 - 4 } Site & Female & 1 & 3 & \\
\cline { 2 - 4 } & Single & 4 & 3 & \multirow{2}{*}{0.198} \\
\hline \multirow{2}{*}{$\begin{array}{c}\text { BM } \\
\text { involvement }\end{array}$} & Multiple & 1 & 4 & \\
\cline { 2 - 4 } & Yes & 4 & 5 & \multirow{2}{*}{0.735} \\
\hline
\end{tabular}

\begin{tabular}{|l|l|l|} 
Code & Drug & Dose \\
\hline V & Vincristine & $1.5 \mathrm{mg} / \mathrm{m}^{2}$ push over 1 minute \\
\hline I & Ifosfamide & $\begin{array}{l}2 \mathrm{gm} / \mathrm{m}^{2} \text { in } 500 \mathrm{ml} \mathrm{NS} \text { over } 1 \mathrm{hr} \text { followed by Mesna } 400 \mathrm{mg} / \mathrm{m}^{2} \mathrm{IV} \\
\text { push given at } 0,4,8 \mathrm{hrs} \text {. of starting Ifosfamide }\end{array}$ \\
\hline E & Etoposide & $100 \mathrm{mg} / \mathrm{m}^{2}$ in $250 \mathrm{ml} \mathrm{NS}$ over $1 \mathrm{hr}$ \\
\hline A & Adriamycin & $60 \mathrm{mg} / \mathrm{m}^{2}$ in $500 \mathrm{ml} \mathrm{NS}$ over $6 \mathrm{hr}$ \\
\hline C & Cyclophosphamide & $600 \mathrm{mg} / \mathrm{m}^{2}$ in $200 \mathrm{ml} \mathrm{NS}$ over 30 minutes \\
\hline D & Actinomycin D & $1 \mathrm{mg} / \mathrm{m}^{2}$ slow IV push \\
\hline
\end{tabular}


Table 3: Demography of serial patients

\begin{tabular}{|l|l|l|l|l|l|c|c|c|c|}
\hline SN & Name & Age & Sex & \multicolumn{1}{|c|}{ Site } & $\begin{array}{c}\text { No of } \\
\text { Site }\end{array}$ & $\begin{array}{c}\text { BM } \\
\text { involved } \\
\text { Osseous) }\end{array}$ & $\begin{array}{c}\text { Initial } \\
\text { Volume } \\
\text { (cc) }\end{array}$ & $\begin{array}{c}\text { Volume } \\
\text { group }\end{array}$ & $\begin{array}{c}\text { PFS } \\
\text { months }\end{array}$ \\
\hline 1 & PN & 22 & M & Humerus & Single & Yes & 76 & 1 & 71 \\
\hline 2 & KM & 16 & F & Humerus & Multiple & Yes & 104 & 2 & 79 \\
\hline 3 & PM & 15 & M & Pelvis & Single & No & 300 & 2 & 51 \\
\hline 4 & NB & 1 & M & Axilla & Single & Yes & 20 & 1 & 74 \\
\hline 5 & AA & 32 & F & Pelvic & Multiple & Yes & 1050 & 2 & $19 \#$ \\
\hline 6 & IPS & 32 & M & Mental & Single & Yes & 45 & 1 & 58 \\
\hline 7 & LN & 0.58 & F & Jaw & Multiple & No & 60 & 1 & 49 \\
\hline 8 & BM & 17 & M & Calveria & Multiple & Yes & 150 & 2 & $34 \#$ \\
\hline 9 & RY & 2 & M & Glutei & Single & Yes & 100 & 1 & 30 \\
\hline 10 & AS & 14 & M & Humerus & Multiple & Yes & 300 & 2 & 27 \\
\hline 11 & HAH & 26 & F & Femur & Single & No & 504 & 2 & 24 \\
\hline 12 & AL & 18 & M & Femur & Single & Yes & 478 & 2 & 46 \\
\hline
\end{tabular}

\# dead

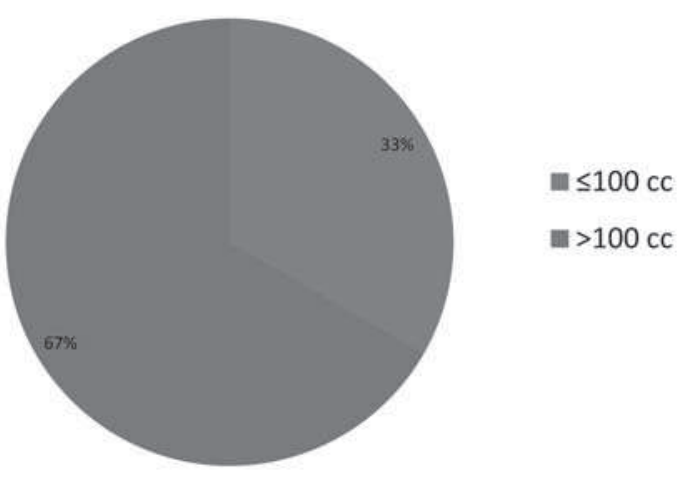

Figure 1: Initial tumor volume

PFS of patients with initial tumor volume $\leq 100 \mathrm{cc}$ ranged from 30 months to 74 months (mean 56.4 months) while that for $>100 \mathrm{cc}$ ranged from 19 months to 79 months (mean 40 months). The $\mathrm{p}$ value was 0.701 which was not statistically significant (Table 4 ), however there was trend towards better survival in patients with initial tumor volume $\leq 100 \mathrm{cc}$.

Table 4: Progression Free Survival according to initial tumor volume

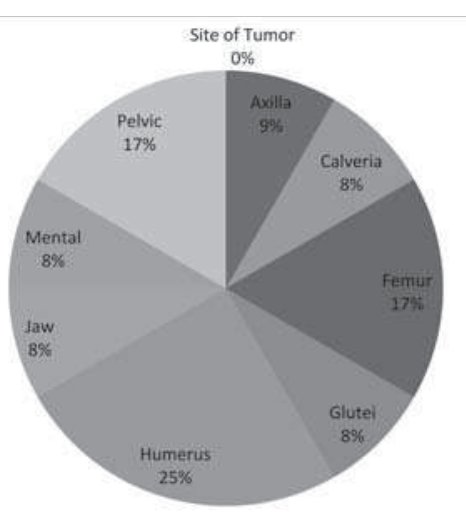

Figure 2: Site of tumor

\section{DISCUSSION}

Ewing's sarcoma belongs to the Ewing Family of Tumors (EFT), which comprises a group of small round cell neoplasm of neuroectodermal origin and includes Ewing sarcoma of bone, primitive neuroectodermal tumors (PNETs), Askin-Rosai tumor (PNET of chest wall) and extra osseous Ewing sarcoma.

EFT may arise in osseous or non-osseous sites and

\begin{tabular}{|c|c|c|c|}
\multirow{2}{*}{ Parameter } & \multicolumn{2}{|c|}{ Group } & \multirow{2}{*}{ P value } \\
\cline { 2 - 3 } & $\mathbf{A} \leq \mathbf{1 0 0} \mathbf{c c}$ & $\mathbf{B}>\mathbf{1 0 0} \mathbf{~ c}$ & \multirow{2}{*}{0.701} \\
\hline PFS Minimun & 30 & 19 & \\
\hline PFS Maximum & 74 & 40 & \\
\hline Mean & 56.4 & \\
\hline
\end{tabular}

Me dic a l J o u r n l of Shree Birendra Hos pital 
in multiple locations, including the soft tissues anywhere in the body such as the paravertebral and thoracic areas. ${ }^{6}$ Ewing's sarcoma is the second most common primary bone tumor in pediatric patients after Osteosarcoma, accounting for approximately $2 \%$ of childhood malignancies. ${ }^{7}$ EFT accounts for 10 to $15 \%$ of all malignant bone tumors, with peak incidence between 10 and 15 years of age. Only $20 \%$ to $30 \%$ are diagnosed in the first decade of life. ${ }^{8}$

EFT is a curable cancer of children and young adults (CYAs). Within this entity, there are diseases characteristics that prognosticate for longer survival after intensive chemo radiotherapy protocols. Initial disease volume is one such characteristic.

EFT belongs to the group of sarcomas associated with unique chromosomal translocations that give rise to specific fusion transcripts. ${ }^{2,9}$ Eighty-five percent of Ewing's sarcoma are associated with the translocation $\mathrm{t}(11 ; 22)(\mathrm{q} 24 ; \mathrm{q} 12)$ resulting in the fusion of the EWS and FLI1 genes. Another $10 \%$ to $15 \%$ of tumors are associated with the translocation $\mathrm{t}(21 ; 22)(\mathrm{q} 22 ; \mathrm{q} 12)$ that generates the EWS-ERG fusion gene. In both cases, a portion of the EWS gene on chromosome 22 is fused to part of another gene. Both FLI (on chromosome 11) and ERG (on chromosome 21) are members of the ETS family of transcription factors.

The lower extremity is the most common primary site for Ewing's sarcoma, accounting for approximately $40 \%$ to $45 \%$ of newly diagnosed cases, with about half of these occurring in the femur. ${ }^{10}$ The pelvis is the second most common primary site for Ewing's sarcoma, accounting for an additional $20 \%$ to $25 \%$ of new cases. Pelvic tumors may arise in the ilium, ischium, pubic bone, or sacrum.

Upper extremity sites account for another $10 \%$ of new diagnoses, with the majority of these cases occurring in the humerus. Chest wall lesions make up $15 \%$ to $20 \%$ of primary Ewing's sarcomas, representing the most frequent chest wall tumor in children. The remaining osseous Ewing's sarcomas originate from the vertebrae, mandible, and skull.

EFT can affect non-osseous structures as well, and these usually occur in the soft tissues, but have also been described to arise in the gastrointestinal tract, kidney, adrenal gland, lung, and other rare sites. ${ }^{10}$ Metastatic disease is present in approximately $25 \%$ of patients at initial diagnosis. ${ }^{11}$ Most frequent sites of metastases are the lungs, bones, and bone marrow.

Abnormal laboratory findings at the time of diagnosis may include elevated LDH and alkaline phosphatase. LDH is useful as a gauge of tumor burden, and usually falls with effective therapy and rises with disease recurrence. ${ }^{12}$ Ewing sarcoma is one of the small round blue cell tumors. The differential diagnosis includes lymphoma, neuroblastoma, retinoblastoma and rhabdomyosarcoma.

MRI provides the most precise definition of the local extent of the tumor. Lesions that originate in the long bones characteristically involve the diaphyses, with extension toward the metaphyses. On plain films, a lytic or mixed lytic-sclerotic lesion is usually identified in the bone. Multilamellated periosteal reaction (onion skin appearance) and lifting of the periosteum (Codman's triangle), or less frequently radiating bone spicules, may be present.

With most modern treatment regimens, the diseasefree survival for patients with localized disease may approach $70 \%$, while the overall survival (OS) may be $>80 \%{ }^{13,14} \mathrm{~A}$ number of clinical and pathologic features have been recently been reported to have a prognostic significance in non-metastatic Ewing's sarcoma treated with chemotherapy, including the site and size of the lesion, the age and sex of the patient, the serum LDH level, the presence of anemia, the interval between the onset of symptoms and diagnosis the presence of fever, the number and type of drugs used in chemotherapy the histologic response of the tumor to primary chemotherapy and the type of local treatment (surgery, radiation therapy, or both). ${ }^{15,16,17}$

Surgery is preferred approach to all resectable tumors. Radiotherapy is indicated for patients with no function preserving surgical option or whose tumors have been excised with inadequate margins. In surgically treated patients, the most important prognostic factor is chemotherapy-induced necrosis. ${ }^{18}$

Size of tumor at the time of diagnosis was found to be significant factor for predicting local and distant recurrence of tumor. ${ }^{19}$ In our study, 12 patients were managed on the EFT 2001 protocol. Patients with low initial disease volume had better survival as compared to patients with high disease volume. Patients with tumor volume $\leq 100 \mathrm{cc}$ were alive for a mean 56.4 months compared to 40 months for patients with tumor volume $>100 \mathrm{cc}$, while 2 patients with tumor volume $>100 \mathrm{cc}$ died at 19 months and 34 months of follow up.

Progression free survival (PFS) of patients with initial tumor volume $\leq 100 \mathrm{cc}$ ranged from 30 months to 74 months (mean 56.4 months) while that for $>100 \mathrm{cc}$ ranged from 19 months to 79 months (mean 40 months). 
The $p$ value was 0.701 which was not statistically significant. However there was trend towards better survival in patients with initial tumor volume $\leq 100 \mathrm{cc}$.

\section{CONCLUSION}

Though very small number of patients was included in this study, there was trend towards better PFS in patients with smaller tumor volume at presentation.

\section{REFERENCES}

1. Devita Jr. VT, Lawrence TS, Rosenberg SA. Devita, Hellman and Rosenberg's Cancer Principles \& Practice of Oncology, 8th ed. Wolters Kluwer:Lippincott Williams \& Wilkins;2008

2. Lazar A, Abruzzo LV, Pollock RE, et al. Molecular diagnosis of sarcomas: chromosomal translocations in sarcomas. Arch Pathol Lab Med 2006;130:1199. PMid:16879024

3. Gibel V, Jtirgens H, Etspiiler G, et al: Prognostic significance of tumor volume in localized Ewing's sarcoma of bone in children and adolescents. $\mathrm{J}$ Cancer Res Clin Oncol. 1987; 113:187-1. http:// dx.doi.org/10.1007/BF00391442

4. Paulussen $M$, Ahrens S, Dunst J, et al: Localized Ewing tumor of bone: Final results of the cooperative Ewing's Sarcoma Study CESS 86. J Clin Oncol., 2001;19:1818-29. PMid:11251014

5. Oken, M.M., Creech, R.H., Tormey, D.C., Horton, J., Davis, T.E., McFadden, E.T., Carbone, P.P.: Toxicity And Response Criteria Of The Eastern Cooperative Oncology Group. Am J Clin Oncol. 1982;5:649-55.http://dx.doi. org/10.1097/00000421-198212000-00014. PMid:7165009

6. Rodriguez-Galindo C, Navid F, Khoury J, et al. Ewing sarcoma family of tumors. In: Pappo A, ed. Pediatric bone and soft tissue sarcomas. New York: Springer, 2006:181. http://dx.doi.org/10.1007/3540-29447-3_9

7. Spector LG, Ross JA, Nagarajan R. Epidemiology of bone and soft tissue sarcomas. In: Pappo A, ed. Pediatric bone and soft tissue sarcomas. New York: Springer, 2006:1. http://dx.doi.org/10.1007/3540-29447-3_1

8. Ries L, Smith M, Gurney J, et al. Cancer incidence and survival among children and adolescents: United States SEER Program 1975-1995.
Bethesda, MD: National Cancer Institute; 1999. Surveillance, Epidemiology, and End Results Program publication 99-4649.

9. Riggi N, Stamenkovic I. The biology of Ewing sarcoma.Cancer Lett 2007. http:// dx.doi.org/10.1016/j.canlet.2006.12.009 PMid:17250957

10. Bernstein $\mathrm{M}$, Kovar $\mathrm{H}$, Paulussen $\mathrm{M}$, et al. Ewing's sarcoma family of tumors: current management. Oncologist 2006;11:503. http:// dx.doi.org/10.1634/theoncologist.11-5-503

11. Rodriguez-Galindo C, Spunt SL, Pappo AS. Treatment of Ewing sarcoma family of tumors: current status and outlook for the future. Med Pediatr Oncol 2003;40:276. http://dx.doi. org/10.1002/mpo.10240 PMid:12652615

12. Farley FA, Healey JH, Caparros-Sison B, et al. Lactase dehydrogenase as a tumor marker for recurrent disease in Ewing's sarcoma. Cancer 1987;59:1245. http://dx.doi.org/10.1002/1097$0142(19870401) 59: 7<1245$ : : A ID CNCR2820590702>3.0.CO;2-Z

13. Craft AW, Paulussen $M$, Douglas $C$ et al. EICESS 92-early results of an international Ewingstumour study. Med PediatrOncol 2000; 35: 191.

14. Rodriguez-Galindo C, Spunt SL, Pappo AS. Treatment of Ewing sarcoma family of tumors: current status and outlook for the future. Med Pediatr Oncol 2003; 40: 276-287. http://dx.doi. org/10.1002/mpo.10240 PMid:12652615 